\title{
Hypertension Is Associated with White Matter Disruption in Apparently Healthy Middle-Aged Individuals
}

\author{
(D). Hannawi, (DL.R. Yanek, DB.G. Kral, DD. Vaidya, DL.C. Becker, DD.M. Becker, and (DP.A. Nyquist
} O- $\equiv$

\begin{abstract}
BACKGROUND AND PURPOSE: Traditional cardiovascular risk factors have been associated with white matter disease. Because hypertension results in vascular stiffness and impaired cerebral perfusion, we hypothesized that it would be the most relevant risk factor for microstructural white matter disruption in apparently healthy middle-aged individuals with a family history of early-onset coronary artery disease.
\end{abstract}

MATERIALS AND METHODS: This was a cross-sectional analysis of participants in the Genetic Study of Atherosclerosis Risk with DTI. Regional fractional anisotropy of 181 segmented brain regions was measured using Eve WM Atlas. Risk factors were examined using univariate analysis for 48 regions representing deep WM structures. Minimal multivariable linear regression models adjusting for age, sex, and race and maximal linear regression models adjusting for cardiovascular risk factors were performed for regions meeting the Bonferroni threshold in the initial analysis.

RESULTS: Included were 116 subjects (mean age, $49 \pm 11$ years; $57 \%$ men) with a moderate load of cardiovascular risk factors. Subjects with hypertension had significantly lower regional fractional anisotropy in the right cingulum and left stria terminalis in the minimal and maximal regression models. Additionally, there was lower regional fractional anisotropy in the left fornix in the maximal model and right sagittal stratum in the minimal model. Systolic blood pressure values were significantly associated with regional fractional anisotropy in the left superior longitudinal fasciculus in the maximal model. There were no significant differences among regional fractional anisotropy values for other cardiovascular risk factors.

CONCLUSIONS: In middle-aged apparently healthy individuals with susceptibility to vascular disease, among all known cardiovascular risk factors, hypertension was associated with microstructural WM disruption.

ABBREVIATIONS: $\mathrm{BMI}=$ body mass index; $\mathrm{BP}=$ blood pressure; $\mathrm{CSVD}=$ cerebral small vessel disease; $\mathrm{FA}=$ fractional anisotropy; $\mathrm{LDL}=$ low-density lipoprotein; rFA = regional fractional anisotropy

W

hite matter hyperintensities, frequently incidentally observed on brain MR imaging, have been attributed to cere-

Received February 26, 2018; accepted after revision September 21.

From the Department of Neurology (Y.H.), Division of Cerebrovascular Diseases and Neurocritical Care, Ohio State University, Columbus, Ohio; GeneSTAR Research Program (L.R.Y., B.G.K., D.V., L.C.B., D.M.B.), Department of Medicine, Johns Hopkins University School of Medicine, Baltimore, Maryland; and Department of Anesthesiology and Critical Care Medicine (P.A.N.), Neurosciences Critical Care, and Department of Neurology (P.A.N.), Johns Hopkins University, Baltimore, Maryland.

This work was supported by the National Institutes of Health/National Institute of Neurological Disorders and Stroke grant NS062059; and the National Center for Research Resources and the National Center for Advancing Translational Sciences, National Institutes of Health, to the Johns Hopkins Institute for Clinical and Translational Research, grant ULIRR025005.

Paper previously presented at: International Stroke Conference, February 22-24, 2017; Houston, Texas.

Please address correspondence to: Yousef Hannawi, MD, Division of Cerebrovascular Diseases and Neurocritical Care, Department of Neurology, Ohio State Uni-

bral small vessel disease (CSVD). ${ }^{1}$ Histopathologically, WM hyperintensity areas show nonspecific changes of gliosis, myelin and axonal loss, tissue rarefaction, and lipohyalinosis. ${ }^{2}$ The exact mechanisms leading to CSVD remain undefined. ${ }^{3}$ It has been hypothesized that interactions between genetics and environmental factors lead to small-vessel changes causing white matter damage secondary to vasculopathy and arteriosclerosis, resulting in hypoxia and hypoperfusion. These events are influenced by altered cerebrovascular autoregulation as well as endothelial and blood-brain barrier dysfunction. ${ }^{4}$ Among traditional cardiovascular risk factors, hypertension has been consistently found to be

versity, 333 West 10th Ave, Graves Hall 3170D, Columbus, $\mathrm{OH} 43210$; e-mail: yousefhannawi@yahoo.com

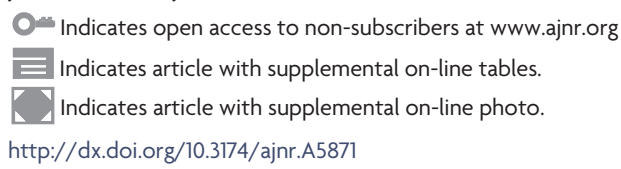


related to CSVD. ${ }^{5}$ Rat models of hypertension develop diffuse WM disease. ${ }^{6}$ Human studies have linked hypertension directly to arterial stiffness, leading to WM changes related to CSVD. ${ }^{7-9}$ Other traditional atherogenic risk factors such as diabetes, smoking, and hyperlipidemia have been less consistently linked to CSVD compared with hypertension. ${ }^{10,11}$ DTI has emerged as a valuable tool for assessment of WM in health and disease through measurement of signal attenuation in the fiber tracts. ${ }^{12}$ DTI has an advantage over conventional T2 or FLAIR sequences due to improved mapping and 3D diffusion characterization incorporating spatial location. This property can be used to describe the magnitude, degree, and orientation of diffusion anisotropy. ${ }^{12}$

Fractional anisotropy (FA) is a sensitive biomarker for WM integrity, reflecting axonal loss or demyelination. ${ }^{12}$ Decreased FA has been found in cases of demyelination, edema, or inflammation. ${ }^{12}$ In patients with CSVD, impaired WM microstructure has been detected by DTI studies. ${ }^{13}$ In Nyquist et al, ${ }^{14}$ our group demonstrated that WM hyperintensity contributes to subclinical psychomotor impairment in apparently healthy subjects. In the current work, we aimed to investigate the relationship of various atherogenic vascular risk factors with the impairment of WM microstructure as measured by DTI. We hypothesized that early changes in regional WM can be detected by DTI in apparently healthy middle-aged individuals and that these changes are primarily associated most strongly with hypertension.

\section{MATERIALS AND METHODS Sample and Recruitment}

We selected healthy participants who underwent DTI as part of the Genetic Study of Atherosclerosis Risk (GeneSTAR) silent stroke study. GeneSTAR is an ongoing prospective study of vascular disease risk factors, occult coronary artery disease and cerebrovascular disease, and incident coronary artery disease and strokes in 3533 initially healthy family members ascertained from probands hospitalized with documented coronary artery disease younger than 60 years of age. ${ }^{14}$ Of these initially healthy family members, 808 were screened with cranial MR imaging for WM hyperintensity; of those, 116 healthy subjects had DTI sequences.

The 116 participants included apparently healthy asymptomatic siblings, their offspring, and the offspring of the probands who were 30-72 years of age. None had a known history of coronary artery disease, stroke, or transient ischemic attacks and represented 97 families. Exclusion criteria included the following: chronic corticosteroids, life-threatening diseases, neurologic diseases impairing accurate MR imaging interpretation, implanted metals prohibiting MR imaging, atrial fibrillation, and symptomatic cardiovascular or cerebrovascular disease. The study was approved by the Johns Hopkins Medicine institutional review board (NA_00002856). All participants provided written informed consent before screening.

\section{Participant Screening and Data Collection}

Each participant was examined by a physician. All participants were screened for coronary artery disease and stroke risk factors, including hypertension, diabetes, total cholesterol, low-density lipoprotein (LDL) cholesterol, high-density lipoprotein cholesterol, body mass index (BMI), and cigarette smoking. ${ }^{15}$ Race was self-reported. Height and weight were measured and BMI was calculated. ${ }^{16}$ Current cigarette smoking was defined by self-report of any smoking within the past month and/or 2 expired carbon monoxide levels of $\geq 8 \mathrm{ppm}$. Blood pressure (BP) was measured 3 times during 1 day, and the average systolic and diastolic BP was used to characterize BP according to guidelines of the American Heart Association. ${ }^{17}$ Hypertension was defined as an average measured BP $\geq 140 \mathrm{~mm} \mathrm{Hg}$ systolic or $90 \mathrm{~mm} \mathrm{Hg}$ diastolic and/or use of antihypertensive drugs. Blood for measurements of cholesterol and glucose levels was collected following a 12-hour fast overnight. Type 2 diabetes was defined as a physician-diagnosed history, a fasting glucose level of $\geq 126 \mathrm{mg} / \mathrm{dL}$, and/or use of hypoglycemic antidiabetic medications. Total cholesterol, highdensity lipoprotein, and triglyceride levels were measured according to the United States Centers for Disease Control standardized methods. ${ }^{18}$ LDL cholesterol was estimated using the Friedewald formula. ${ }^{19}$

\section{MR Imaging Acquisition}

MR imaging was acquired on a 3T Achieva imaging unit (Philips Healthcare, Best, the Netherlands) according to standardized protocols. We acquired the following series: 1) axial T1-weighted MPRAGE—TR, $10 \mathrm{~ms}$; TE, $6 \mathrm{~ms}$; voxel size, $0.75 \times 0.75 \times 1 \mathrm{~mm}^{3}$; contiguous slices; FOV, $240 \times 240 \mathrm{~mm}$; matrix, $320 \times 320 \mathrm{~mm}$; ) axial spin-echo T2 images-TR, $4685 \mathrm{~ms}$; TE, $78 \mathrm{~ms}$; voxel size, $0.47 \times 0.47 \times 3 \mathrm{~mm}^{3}$; contiguous slices; FOV, $240 \times 240 \mathrm{~mm}$; matrix, $512 \times 512$; 3) DTI-TR, $7043 \mathrm{~ms}$; TE, $71 \mathrm{~ms}$; voxel size, $0.83 \times 0.83 \times 2.2 \mathrm{~mm}^{3}$; contiguous slices; FOV, $212 \times 212 \mathrm{~mm}$; matrix, $256 \times 256$; 32 directions; b-value $=700 \mathrm{~s} / \mathrm{mm}^{2}$.

\section{DTI Processing and Analysis}

DTI was preprocessed and analyzed using an MR imaging studio package (DTIstudio, DiffeoMap, ROIEditor) publicly available at www.mristudio.org through Johns Hopkins University. First, all images (T1, T2, DWI) were reviewed by a board-certified physician in neurology and neurocritical care (Y.H.) for the presence of any rotation, motion artifacts, or eddy current artifacts in the DTI studio image viewer application, which was followed by tensor calculation according to the standardized steps in DTIstudio. ${ }^{20}$ 3D FA, mean diffusivity, and radial diffusivity maps were created following tensor calculation.

WM segmentation was performed in the subject's native space according to the Eve WM Atlas in the DifeoMap and ROIEditor package software. ${ }^{21}$ First, FA and mean $\mathrm{B}_{0}$ maps were skullstripped in ROIEditor. Following skull-stripping, a dual-channel large deformation diffeomorphic mapping algorithm was used in DifeoMap to perform linear and nonlinear registration to the Eve WM Atlas JHU-MNI-SS-SS template in the Montreal Neurological Institute space. This step allowed automated segmentation of the FA subject map in native space using the inverse registration matrix into 181 regions (On-line Figure $A-C$ ). The mean regional FA value ( $\mathrm{rFA}$ ) was calculated in each of the regions by choosing a voxel FA threshold of $\geq 0.2$ to exclude voxels that included CSF and gray matter. Then, 48 regions of the Atlas representing the deep white matter regions primarily affected by CSVD were se- 
lected for the subsequent statistical analysis (On-line Table 1 and On-line Figure $D-F)$.

\section{Statistical Analysis}

Statistical analysis was performed using SAS software (Version 9.2; SAS Institute, Cary, North Carolina). Univariable analysis comparing the mean rFA between participants with and without current smoking, hypertension, and diabetes was completed using $t$ tests. Spearman rank order correlations were used to test the associations among continuous variables, including: systolic BP,

Table 1: Baseline characteristics of the study cohort $(N=116)$

\begin{tabular}{lc}
\hline \multicolumn{1}{c}{ Characteristic } & Mean or \% \\
\hline Age (yr) & $49.6 \pm 11.1$ \\
Education (yr) & $14.4 \pm 2.8$ \\
Male sex & $49.1 \%$ \\
African American race & $40.5 \%$ \\
Hypertension & $36.2 \%$ \\
Diabetes & $12.0 \%$ \\
LDL cholesterol (mg/dL) & $110.4 \pm 39.2$ \\
Current smoking status & $23.3 \%$ \\
Systolic blood pressure (mm Hg) & $122.7 \pm 15.6$ \\
Diastolic blood pressure (mm Hg) & $77.5 \pm 8.9$ \\
Glucose level (mg/dL) & $98.8 \pm 29$ \\
Triglyceride level (mg/dL) & $111.6 \pm 68.3$ \\
BMI (kg/m $\mathrm{m}^{2}$ ) & $28.7 \pm 5.5$ \\
\hline
\end{tabular}

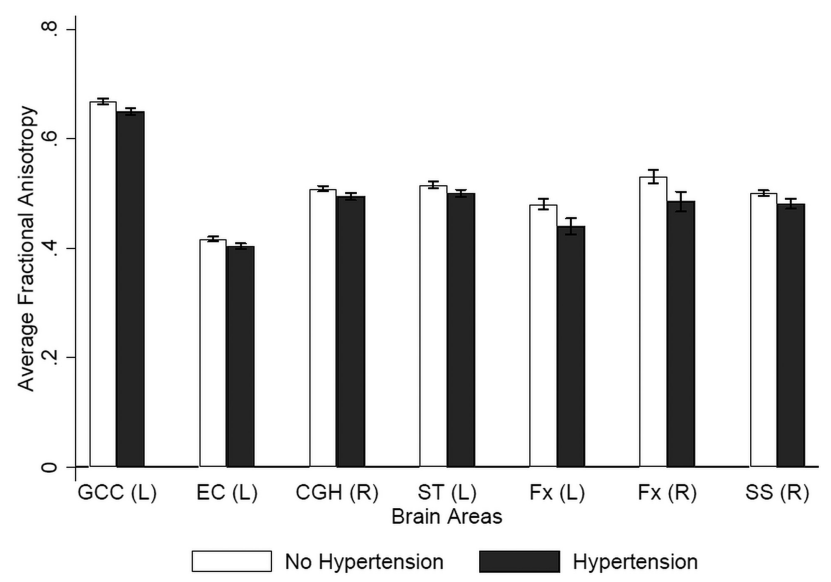

FIG 1. Bar chart of the regions that showed a significant difference in rFA between subjects with and without hypertension. CGH (R) indicates right cingulum; $E C(L)$, left external capsule; $F x(L)$, left fornix; Fx $(\mathrm{R})$, right fornix; GCC (L), left genu of the corpus callosum; SS (R), right sagittal stratum; ST (L), left stria terminalis.

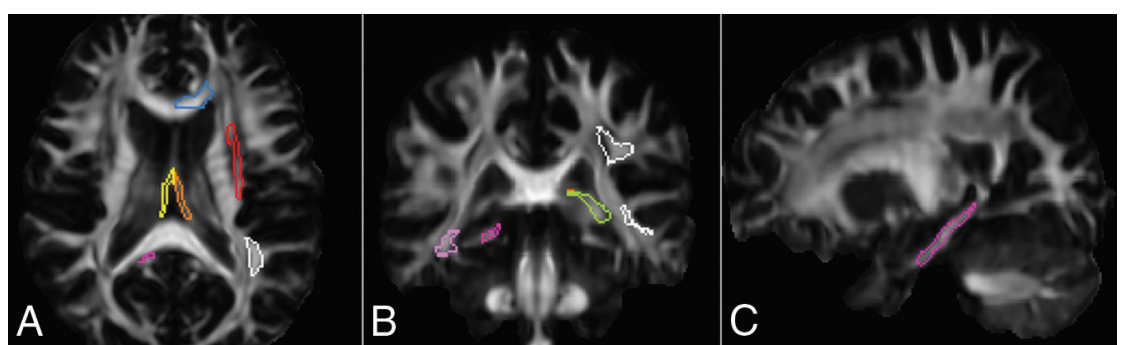

FIG 2. Axial, coronal, and sagittal sections of the FA map, showing areas, in distinct colors, that demonstrate a significant difference of rFA between patients with and without hypertension and areas that show correlation of rFA with systolic blood pressure. Magenta indicates right cingulum; red, left external capsule; orange, left fornix; yellow, right fornix; blue, left genu of the corpus callosum; pink, right sagittal stratum; green, left stria terminalis; white, left superior longitudinal fasciculus. diastolic BP; total cholesterol, triglyceride, high-density lipoprotein cholesterol, LDL cholesterol, and blood glucose levels; and BMI with a mean rFA. The significance threshold was defined using the Bonferroni method for adjustment for multiple comparisons as $P \leq .001$ (.05/48 rFA regions). A minimal linear regression model predicting $\mathrm{rFA}$ and adjusting for age, sex, and race was performed for the regions that met the Bonferroni significance threshold. Then, to understand the effect of the combination of atherogenic risk factors on rFA, we performed a maximal linear regression model predicting $\mathrm{rFA}$ and adjusting for age, sex, race, hypertension, diabetes, total cholesterol level, BMI, and smoking for these regions.

\section{RESULTS}

The study sample consisted of 116 middle-aged participants (mean age, $49.6 \pm 11$ years; $49.1 \%$ men; $40.5 \%$ African American), well-educated with moderate vascular risk factors (Table 1). Review of T2 sequences did not reveal any stroke or localized WM hyperintensity. WM hyperintensity involving the periventricular and deep WM areas was largely symmetric without predilection to any specific areas of the selected WM regions. Participants with hypertension showed widespread reduced rFA compared with participants with normal BP meeting the Bonferroni threshold $(\leq 0.001)$ in the left genu of the corpus callosum, left external capsule, right cingulum, left stria terminalis, bilateral fornices, and right sagittal stratum (On-line Table 2 and Figs 1 and 2). This relationship remained significant in the minimal regression model, after adjusting for age, sex, and race, in the right cingulum; left stria terminalis; and right sagittal stratum (Table 2). Additionally, the relationship remained significantly independent of other atherogenic vascular risk factors in the maximal linear regression model in the right cingulum, left stria terminalis, and left fornix (Table 2). The mean rFA correlated with the average systolic BP in the left superior longitudinal fasciculus (On-line Table 3 and Figs 2 and 3). There was a trend toward significance of the relationship of the rFA of this region with hypertension in the minimal regression model $(P=.08)$. However, this relationship was significant in the maximal regression model following adjustment for other vascular risk factors (Table 3 ).

Notably, rFA was not significantly associated with diabetes or current smoking status in any of the regions (On-line Tables 4 and 5). Additionally, rFA was not significantly correlated with blood glucose, LDL, high-density lipoprotein, total cholesterol, and triglyceride levels; diastolic BP; and $\mathrm{BMI}$ in any of the regions (On-line Tables 6-12).

\section{DISCUSSION}

In this cross-sectional study, we show that decreased $\mathrm{rFA}$, reflecting microstructural WM disruption, is strongly associated with hypertension in middleaged apparently healthy subjects at increased risk for vascular disease in the deep WM regions of the brain. We did not observe additional associations between rFA and other traditional athero- 
Table 2: Minimal and maximal regression models predicting mean rFA of the WM regions that were significantly associated with hypertension in the univariate analysis

\begin{tabular}{|c|c|c|c|c|c|c|c|c|c|c|c|}
\hline \multirow[b]{2}{*}{ White Matter Structure } & \multicolumn{2}{|c|}{ Normotensive } & \multicolumn{2}{|c|}{ Hypertensive } & \multirow[b]{2}{*}{$T$ test $P$ Value } & \multicolumn{3}{|c|}{$\begin{array}{c}\text { Minimal } \\
\text { Regression Model }\end{array}$} & \multicolumn{3}{|c|}{$\begin{array}{c}\text { Maximal } \\
\text { Regression Model }\end{array}$} \\
\hline & Mean & SD & Mean & SD & & $\boldsymbol{\beta}$ & SE & $P$ Value & $\boldsymbol{\beta}$ & SE & $P$ Value \\
\hline Genu of corpus callosum (L) & 0.668 & 0.02 & 0.651 & 0.02 & .0003 & -0.201 & 0.202 & .32 & -0.286 & 0.195 & .14 \\
\hline External capsule (L) & 0.417 & 0.02 & 0.403 & 0.02 & .0002 & -0.191 & 0.202 & .34 & -0.162 & 0.228 & .48 \\
\hline Cingulum (R) & 0.509 & 0.02 & 0.494 & 0.02 & .0004 & -0.586 & 0.193 & $.002^{\mathrm{a}}$ & -0.635 & 0.202 & $.002^{\mathrm{a}}$ \\
\hline Stria terminalis (L) & 0.516 & 0.02 & 0.5 & 0.02 & .0008 & -0.446 & 0.217 & $.04^{\mathrm{a}}$ & -0.487 & 0.216 & $.03^{\mathrm{a}}$ \\
\hline Fornix (L) & 0.48 & 0.04 & 0.441 & 0.05 & $<.0001$ & -0.267 & 0.172 & .12 & -0.51 & 0.191 & $.008^{a}$ \\
\hline Fornix (R) & 0.531 & 0.05 & 0.486 & 0.06 & $<.0001$ & 0.026 & 0.171 & .88 & -0.068 & 0.186 & .72 \\
\hline Sagittal stratum (R) & 0.501 & 0.02 & 0.482 & 0.02 & .0006 & -0.527 & 0.201 & $.009^{a}$ & -0.256 & 0.292 & .38 \\
\hline
\end{tabular}

Note:- $-L$ indicates left, R, right; SE, standard error; SD, standard deviation.

a Significant; $P<.05$.

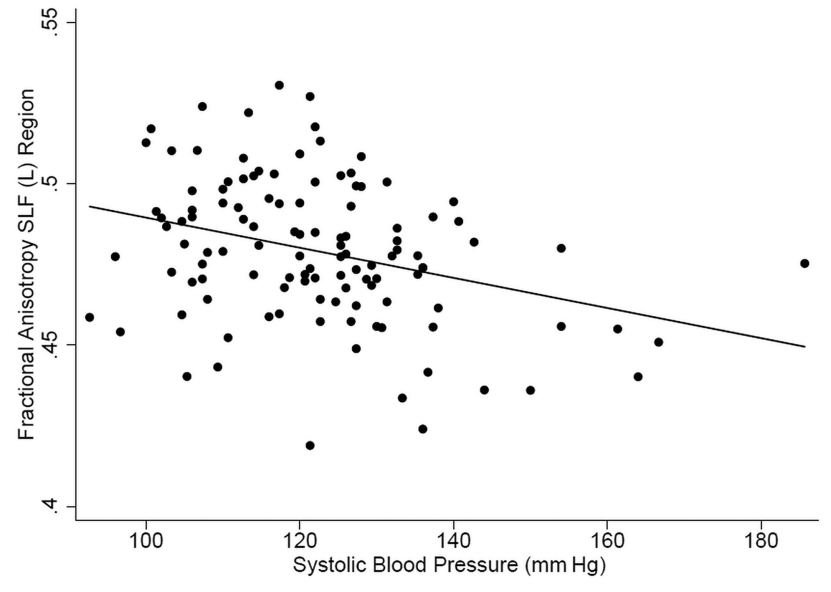

FIG 3. Scatterplot showing the relationship of rFA of the left superior longitudinal fasciculus and systolic blood pressure. SLF (L) indicates left superior longitudinal fasciculus.

genic vascular risk factors such as diabetes, total cholesterol level, LDL, BMI, or smoking. The role of DTI in detecting WM disruption in subjects with vascular risk factors has been addressed previously. $^{22-39}$

Hypertension has been consistently associated with decreased FA and elevated mean diffusivity in different WM regions, including normal-appearing WM. ${ }^{24,25,27-31}$ In addition, increased BP values linearly correlated with decreased FA in the right anterior corpus callosum, inferior fronto-occipital fasciculus, and the fibers that project from the thalamus to the superior frontal gyrus in 1 study. ${ }^{22}$ Most of these studies have assessed elderly subjects with an average age of $65.8-83$ years ${ }^{25,27-29}$ or investigated the effect of hypertension in middle life on the development of WM disruption at a later age. ${ }^{31}$ Two previous studies investigated the relationship of systolic BP and WM microstructure at a younger age (39.2-48 years). ${ }^{22,24}$ One of them linked adiposity as measured by waist circumference with BP and WM microstructure. ${ }^{24}$ The second article analyzed the systolic BP relationship with regional DTI metrics by measuring the number of voxels within each WM region that correlated with the systolic BP value. ${ }^{22}$ Our study used a different approach by analyzing the average rFA of a well-defined WM atlas in relation to vascular risk factors. Given the healthy nature of our relatively younger cohort compared with cohorts in the literature, we believe that we captured the disease at an early stage when it had not progressed yet to involve all the subcortical WM in a symmetric fashion. Indeed, our results reflect that by showing a lower rFA of selected WM regions.
Brain DTI of patients with diabetes showed reduced FA using Tract-Based Spatial Statistics (TBSS; http://fsl.fmrib.ox.ac.uk/fsl/ fslwiki/TBSS) in patients with mild cognitive impairment compared with those without it. ${ }^{39}$ A similar analytic method showed a significant decrease in the WM tract DTI metrics in closely related areas to the default mode network in patients with type 2 diabetes compared with healthy controls. ${ }^{38}$ Finally, the Atherosclerosis Risk in Communities (ARIC) neurocognitive study found a relationship between midlife and late-life elevated blood glucose levels and worse WM microstructural integrity in late life. ${ }^{31}$ We did not observe a relationship between diabetes or glucose levels and rFA in our cohort. This is likely secondary to the healthy nature of our subjects, who are cognitively intact, younger in age, and with fewer atherogenic risk factors.

In contrast to diabetes and hypertension, the relationship between WM microstructures and other atherogenic vascular risk factors is modest and inconsistent. The ARIC study did not observe a relationship between lipid levels at midlife and late life with late-life DTI metrics. ${ }^{31}$ However, another study found an association between lipids, especially LDL levels, and WM microstructure integrity in 125 generally healthy older adults (mean age, 68 years). ${ }^{32} \mathrm{BMI}$ was found to be associated with WM microstructure integrity in selected ROIs in a sample of older healthy community participants (mean age, 71.3 years). ${ }^{23}$ The combination of atherogenic vascular risk factors $(\geq 2)$ was associated with a longitudinal drop in FA in WM regions compared with no vascular risk factors in elderly subjects (mean age, 73.9 years). ${ }^{25}$ Finally, smoking was associated with increased FA in WM regions in adolescent/young adult smokers in a recent systematic review. ${ }^{35} \mathrm{An}$ other study of chronic smokers showed decreased FA of the hippocampus in association with decreased memory performance compared with nonsmokers. ${ }^{34}$

In summary, our study cohort is unique because it tests a relatively young and healthy group of subjects who are relatives of patients with coronary artery disease compared with most previous literature that evaluated elderly subjects, patients who have advanced vascular risk factors, or subjects with cognitive impairments. Our findings indicate hypertension as being the most important risk factor in otherwise healthy subjects at early stages of the disease. The identified WM regions in our study likely play important roles in cognition and memory. The stria terminalis and fornix are critical for normal cognitive functioning and memory. ${ }^{40}$ Fornix pathology can be found in Alzheimer disease. The cingulum is known to play a role in exec- 
Table 3: Minimal and maximal regression models predicting mean rFA of the WM region that were significantly associated with systolic blood pressure in the univariate analysis

\begin{tabular}{|c|c|c|c|c|c|c|c|c|}
\hline \multirow[b]{2}{*}{ White Matter Structure } & \multirow{2}{*}{$\begin{array}{l}\text { Spearman } \\
\text { Rank Test }\end{array}$} & \multirow[b]{2}{*}{$P$ Value } & \multicolumn{3}{|c|}{$\begin{array}{c}\text { Minimal } \\
\text { Regression Model }\end{array}$} & \multicolumn{3}{|c|}{$\begin{array}{c}\text { Maximal } \\
\text { Regression Model }\end{array}$} \\
\hline & & & $\boldsymbol{\beta}$ & SE & $P$ Value & $\boldsymbol{\beta}$ & SE & $P$ Value \\
\hline Superior longitudinal fasciculus (L) & -0.309 & .0007 & -0.012 & 0.007 & .08 & -0.014 & 0.006 & $.03^{\mathrm{a}}$ \\
\hline
\end{tabular}

Note:- L indicates left; SE, standard error

a Significant; $P<.05$

utive control, emotion, and episodic memory, and it has been implicated in multiple psychiatric diseases and Alzheimer disease. ${ }^{41}$ The superior longitudinal fasciculus abnormalities on DTI have been attributed to age-related language decline. ${ }^{42}$ Finally, the sagittal stratum carries multiple functional fibers implicated in language and visual function. ${ }^{43}$

Despite available animal and human data suggesting a mechanistic relationship of hypertension to CSVD, the underlying processes leading to these events are yet to be established. ${ }^{4}$ Arterial stiffness has been closely linked to hypertension and aging. Arterial stiffness results from remodeling of the arterial wall secondary to degradation of elastin and accumulation of collagen and calcium deposition. ${ }^{7}$ Measures of arterial stiffness such as the anklebrachial pressure index have been associated with the development of CSVD findings. ${ }^{89}$ Additionally it is well-known that hypertension is associated with arteriosclerosis, which is the main pathologic feature of CSVD, characterized by fibrohyaline material, narrowing of the lumen, and thickening of the vessel wall. ${ }^{2}$ Moreover, hypertension leads to impaired cerebral autoregulation, which results in cerebral hypoxia and WM injury. ${ }^{44}$ It is plausible that hypertension plays an important role in early WM damage compared with other atherogenic risk factors in middleaged apparently healthy subjects. ${ }^{45}$ Recently, an alternative pathway involving disruption of the blood-brain barrier leading to CSVD has been heavily investigated. ${ }^{4,44}$ The exact relationship of hypertension to BBB dysfunction needs to be thoroughly investigated in the future.

Our study has certain limitations, and it should be interpreted within its context. First, given the cross-sectional nature of the study, a mechanistic relationship between the atherogenic vascular risk factors and WM microstructure disruption cannot be ascertained in our sample. Second, more regions of deep WM structures could have been involved in this disease; however, they were not detected given the relatively small sample size. We decided to choose a conservative method for adjustment for multiple comparisons (Bonferroni method) despite the distributed nature of the CSVD in the brain because we aimed to avoid any possibility of finding false-positive results. In addition, an interaction analysis among vascular risk factors and associated WM damage could not be performed due to the relatively small sample size. Finally, we did not examine the severity of hypertension and blood pressure control at baseline to assess its relationship to the severity of WM disease.

\section{CONCLUSIONS}

In apparently healthy middle-aged subjects at increased risk for vascular disease, among traditional risk factors, hypertension is most closely associated with microstructural WM impairment. These findings have implications for patient care by early selec- tion of subjects who are at risk for future cognitive impairment through identification of these impaired tracts. This may even prove to be of further value because novel therapies are being developed for patients with CSVD.

Disclosures: Lisa R. Yanek—RELATED: Grant: National Institutes of Health, Comments: NS062059 from the National Institutes of Health/National Institute of Neurological Disorders and Stroke to Dr Paul Nyquist. Dhananjay Vaidya-RELATED: Grant: National Institutes of Health.* Paul Nyquist-RELATED: Grant: National Institutes of Health. * *Money paid to the institution.

\section{REFERENCES}

1. Pantoni L. Cerebral small vessel disease: from pathogenesis and clinical characteristics to therapeutic challenges. Lancet Neurol 2010;9:689-701 CrossRef Medline

2. Craggs LJ, Yamamoto Y, Deramecourt V, et al. Microvascular pathology and morphometrics of sporadic and hereditary small vessel diseases of the brain. Brain Pathol 2014;24:495-509 CrossRef Medline

3. Wardlaw JM, Smith C, Dichgans M. Mechanisms of sporadic cerebral small vessel disease: insights from neuroimaging. Lancet $\mathrm{Neu}$ rol 2013;12:483-97 CrossRef Medline

4. Ihara M, Yamamoto Y. Emerging evidence for pathogenesis of sporadic cerebral small vessel disease. Stroke 2016;47:554-60 CrossRef Medline

5. Gottesman RF, Coresh J, Catellier DJ, et al. Blood pressure and white-matter disease progression in a biethnic cohort: Atherosclerosis Risk in Communities (ARIC) study. Stroke 2010;41:3-8 CrossRef Medline

6. Bailey EL, Smith C, Sudlow CL, et al. Is the spontaneously hypertensive stroke prone rat a pertinent model of sub cortical ischemic stroke? A systematic review. Int J Stroke 2011;6:434-44 CrossRef Medline

7. Payne RA, Wilkinson IB, Webb DJ. Arterial stiffness and hypertension: emerging concepts. Hypertension 2010;55:9-14 CrossRef Medline

8. Saji N, Shimizu H, Kawarai T, et al. Increased brachial-ankle pulse wave velocity is independently associated with white matter hyperintensities. Neuroepidemiology 2011;36:252-57 CrossRef Medline

9. Saji N, Kimura K, Shimizu H, et al. Silent brain infarct is independently associated with arterial stiffness indicated by cardio-ankle vascular index (CAVI). Hypertens Res 2012;35:756-60 CrossRef Medline

10. Tamura Y, Araki A. Diabetes mellitus and white matter hyperintensity. Geriatr Gerontol Int 2015;15(Suppl 1):34-42 CrossRef Medline

11. Khan U, Porteous L, Hassan A, et al. Risk factor profile of cerebral small vessel disease and its subtypes. J Neurol Neurosurg Psychiatry 2007;78:702-06 Medline

12. Alexander AL, Lee JE, Lazar M, et al. Diffusion tensor imaging of the brain. Neurotherapeutics 2007;4:316-29 CrossRef Medline

13. Maniega SM, Valdés Hernández MC, Clayden JD, et al. White matter hyperintensities and normal-appearing white matter integrity in the aging brain. Neurobiol Aging 2015;36:909-18 CrossRef Medline

14. Nyquist PA, Yanek LR, Bilgel M, et al. Effect of white matter lesions on manual dexterity in healthy middle-aged persons. Neurology 2015;84:1920-26 CrossRef Medline

15. Wang TJ, Massaro JM, Levy D, et al. A risk score for predicting stroke 
or death in individuals with new-onset atrial fibrillation in the community: the Framingham Heart Study. JAMA 2003;290:1049-56 CrossRef Medline

16. Clinical guidelines on the identification, evaluation, and treatment of overweight and obesity in adults: executive summary-Expert Panel on the Identification, Evaluation, and Treatment of Overweight in Adults. Am J Clin Nutr 1998;68:899-917 CrossRef Medline

17. Brook RD, Appel LJ, Rubenfire M, et al; American Heart Association Professional Education Committee of the Council for High Blood Pressure Research, Council on Cardiovascular and Stroke Nursing, Council on Epidemiology and Prevention, and Council on Nutrition, Physical Activity. Beyond medications and diet: alternative approaches to lowering blood pressure: a scientific statement from the American Heart Association. Hypertension 2013;61:1360-83 CrossRef Medline

18. Myers GL, Kimberly MM, Waymack PP, et al. A reference method laboratory network for cholesterol: a model for standardization and improvement of clinical laboratory measurements. Clin Chem 2000;46:1762-72 Medline

19. Friedewald WT, Levy RI, Fredrickson DS. Estimation of the concentration of low-density lipoprotein cholesterol in plasma, without use of the preparative ultracentrifuge. Clin Chem 1972;18:499-502 Medline

20. Jiang $\mathrm{H}$, van $\mathrm{Zijl} \mathrm{PC}, \mathrm{Kim} \mathrm{J}$, et al. DtiStudio: resource program for diffusion tensor computation and fiber bundle tracking. Comput Methods Programs Biomed 2006;81:106-16 CrossRef Medline

21. Oishi K, Faria A, Jiang H, et al. Atlas-based whole brain white matter analysis using large deformation diffeomorphic metric mapping: application to normal elderly and Alzheimer's disease participants. Neuroimage 2009;46:486-99 CrossRef Medline

22. Maillard P, Seshadri S, Beiser A, et al. Effects of systolic blood pressure on white-matter integrity in young adults in the Framingham Heart Study: a cross-sectional study. Lancet Neurol 2012;11: 1039-47 CrossRef Medline

23. Bettcher BM, Walsh CM, Watson C, et al. Body mass and white matter integrity: the influence of vascular and inflammatory markers. PLoS One 2013;8:e77741 CrossRef Medline

24. Allen B, Muldoon MF, Gianaros PJ, et al. Higher blood pressure partially links greater adiposity to reduced brain white matter integrity. Am J Hypertens 2016;29:1029-37 CrossRef Medline

25. Maillard P, Carmichael OT, Reed B, et al. Cooccurrence of vascular risk factors and late-life white-matter integrity changes. Neurobiol Aging 2015;36:1670-77 CrossRef Medline

26. Heye AK, Thrippleton MJ, Chappell FM, et al. Blood pressure and sodium: association with MRI markers in cerebral small vessel disease. J Cereb Blood Flow Metab 2016;36:264-74 CrossRef Medline

27. Rosano C, Abebe KZ, Aizenstein HJ, et al; Health ABC Study. Longitudinal systolic blood pressure characteristics and integrity of white matter tracts in a cohort of very old black and white adults. Am J Hypertens 2015;28:326-34 CrossRef Medline

28. Nitkunan A, Charlton RA, McIntyre DJ, et al. Diffusion tensor imaging and MR spectroscopy in hypertension and presumed cerebral small vessel disease. Magn Reson Med 2008;59:528-34 CrossRef Medline

29. Gons RA, de Laat KF, van Norden AG, et al. Hypertension and cere- bral diffusion tensor imaging in small vessel disease. Stroke 2010;41: 2801-06 CrossRef Medline

30. Yau PL, Hempel R, Tirsi A, et al. Cerebral white matter and retinal arterial health in hypertension and type 2 diabetes mellitus. Int J Hypertens 2013;2013:329602 CrossRef Medline

31. Power MC, Tingle JV, Reid RI, et al. Midlife and late-life vascular risk factors and white matter microstructural integrity: the Atherosclerosis Risk in Communities Neurocognitive Study. J Am Heart Assoc 2017;6 CrossRef Medline

32. Williams VJ, Leritz EC, Shepel J, et al. Interindividual variation in serum cholesterol is associated with regional white matter tissue integrity in older adults. Hum Brain Mapp 2013;34:1826-41 CrossRef Medline

33. Alfaro FJ, Lioutas VA, Pimentel DA, et al. Cognitive decline in metabolic syndrome is linked to microstructural white matter abnormalities. J Neurol 2016;263:2505-14 CrossRef Medline

34. Yuce I, Kantarci M, Keles P, et al. Diffusion tensor imaging of the hippocampus in chronic cigarette smokers. Eur J Radiol 2016;85: 1538-44 CrossRef Medline

35. Gogliettino AR, Potenza MN, Yip SW. White matter development and tobacco smoking in young adults: a systematic review with recommendations for future research. Drug Alcohol Depend 2016;162: 26-33 CrossRef Medline

36. van Bloemendaal L, Ijzerman RG, Ten Kulve JS, et al. Alterations in white matter volume and integrity in obesity and type 2 diabetes. Metab Brain Dis 2016;31:621-29 CrossRef Medline

37. Reijmer YD, Brundel M, de Bresser J, et al; Utrecht Vascular Cognitive Impairment Study Group. Microstructural white matter abnormalities and cognitive functioning in type 2 diabetes: a diffusion tensor imaging study. Diabetes Care 2013;36:137-44 CrossRef Medline

38. Tan X, Fang P, An J, et al. Micro-structural white matter abnormalities in type 2 diabetic patients: a DTI study using TBSS analysis. Neuroradiology 2016;58:1209-16 CrossRef Medline

39. Xiong $Y$, Sui $Y, X u Z$, et al. A diffusion tensor imaging study on white matter abnormalities in patients with type 2 diabetes using tractbased spatial statistics. AJNR Am J Neuroradiol 2016;37:1462-69 CrossRef Medline

40. Thomas AG, Koumellis P, Dineen RA. The fornix in health and disease: an imaging review. Radiographics 2011;31:1107-21 CrossRef Medline

41. Bubb EJ, Metzler-Baddeley C, Aggleton JP. The cingulum bundle: anatomy, function, and dysfunction. Neurosci Biobehav Rev 2018;92: 104-27 CrossRef Medline

42. Madhavan KM, McQueeny T, Howe SR, et al. Superior longitudinal fasciculus and language functioning in healthy aging. Brain Res 2014;1562:11-22 CrossRef Medline

43. Chan-Seng E, Moritz-Gasser S, Duffau H. Awake mapping for lowgrade gliomas involving the left sagittal stratum: anatomofunctional and surgical considerations. J Neurosurg 2014;120:1069-77 CrossRef Medline

44. Iadecola C, Davisson RL. Hypertension and cerebrovascular dysfunction. Cell Metab 2008;7:476-84 CrossRef Medline

45. Walker KA, Power MC, Gottesman RF. Defining the relationship between hypertension, cognitive decline, and dementia: a review. Current Hypertens Rep 2017;19:24 CrossRef Medline 